\title{
Time-lag performance of radiofrequency ablation after percutaneous ethanol injection for the treatment of hepatocellular carcinoma
}

\author{
KAZUTAKA KUROKOHCHI ${ }^{1,2}$, TSUTOMU MASAKI ${ }^{1}$, SEISHIRO WATANABE $^{1}$, SEIJI NAKAI ${ }^{1}$, \\ AKIHIRO DEGUCHI $^{1}$, ASAHIRO MORISHITA ${ }^{1}$, HIROHITO YONEYAMA $^{1}$, TOMOHIRO OHGI $^{1,2}$, \\ MASAHIRO ONO ${ }^{1,2}$, AKIRA YOSHITAKE ${ }^{1,2}$, TAKESHI KAKO $^{2}$, NAOKO OHMACHI $^{2}$, TAKAAKI KIUCHI $^{3}$, \\ TSUYOSHI MAETA ${ }^{2}$, MITSUO YOSHIDA ${ }^{2}$, YOSHIHIRO MORI ${ }^{2}$, FUMIKAZU KOHI ${ }^{2}$ and SHIGEKI KURIYAMA ${ }^{1}$ \\ ${ }^{1}$ Third Department of Internal Medicine, Kagawa University School of Medicine, \\ 1750-1 Ikenobe, Miki-cho, Kita-gun, Kagawa 761-0793; Departments of ${ }^{2}$ Gastroenterolgy and \\ ${ }^{3}$ Radiology, KKR Takamatsu Hospital, 4-18 Tenjinmae, Takamatsu, Kagawa 760-0018, Japan
}

Received October 31, 2005; Accepted December 19, 2005

\begin{abstract}
We have previously reported that the combination therapy of percutaneous ethanol injection and radiofrequency ablation (PEI-RFA) was more effective than RFA alone to induce wider coagulated necrosis for the treatment of hepatocellular carcinoma (HCC). In the present study, the effect of time-lag performance of RFA after PEI was evaluated under the same ablation condition as PEI-RFA by analyzing the volume of coagulated necrosis, the energy requirement for ablation and the amount of ethanol injected into HCC. The comparative study between time-lag PEI-RFA and no timelag PEI-RFA showed that the total energy requirement and the energy requirement per unit volume for whole and marginal coagulated necrosis were significantly smaller in the time-lag group than in the no time-lag PEI-RFA group. In time-lag PEI-RFA, the volume of coagulated necrosis induced positively correlated with the amount of ethanol injected into HCC as previously observed in PEI-RFA treatment. These results suggest that time-lag PEI-RFA can induce comparable coagulated necrosis with a smaller energy requirement than no time-lag PEI-RFA, and that time-lag PEI-RFA is likely to be less invasive than no time-lag PEI-RFA for inducing comparable coagulated necrosis. Thus, time-lag performance of RFA after PEI may make RFA treatment more effective and less invasive for the treatment of patients with HCC.
\end{abstract}

Correspondence to: Dr Shigeki Kuriyama, Third Department of Internal Medicine, Kagawa University School of Medicine, 1750-1 Ikenobe, Miki-cho, Kita-gun, Kagawa 761-0793, Japan

E-mail: skuriyam@med.kagawa-u.ac.jp

Key words: radiofrequency ablation, percutaneous ethanol injection, hepatocellular carcinoma, time-lag performance

\section{Introduction}

Hepatocellular carcinoma (HCC) is a common malignancy worldwide. For the treatment of HCC, several treatment modalities, such as surgical resection, intervention radiology, liver transplantation and local ablation, are applied according to the characteristics of the tumor and the degree of hepatic reserve capacity. For the patients with HCC for whom surgical treatment is not suitable, local treatments are an option. As local treatments, percutaneous ethanol injection (PEI), percutaneous acetate injection (PAI), percutaneous microwave coagulation therapy (PMCT), cryoablation and radiofrequency ablation (RFA) are currently available $(1,2)$. Among the local treatments, PEI and PAI are considered to be effective for the treatment of patients with relatively small-sized encapsulated $\mathrm{HCC}$ of $<3 \mathrm{~cm}$ in diameter. Instead of PEI, which was more frequently performed in the past, RFA now plays a central role in local treatments because it can induce wider coagulated necrosis in fewer sessions than PEI or PAI (3-5). Although RFA has various benefits, such as simplicity and ease of performance, achievement of certain therapeutic effects $(6,7)$, lack of serious side-effects and, more importantly, longer survival intervals than PEI $(8,9)$, the extent of coagulated necrosis induced by RFA is limited and early local tumor recurrence frequently occurs (10). To overcome these weaknesses of routine RFA treatment, we developed a combination therapy of PEI and RFA (PEI-RFA) and reported that PEIRFA could induce wider coagulated necrosis with a smaller energy requirement (11-13). The present study analyzing the effectiveness of PEI-RFA was triggered by an accidental event that happened when PEI-RFA was performed on HCC using an RFA system equipped with an expandable LeVeen needle electrode. When the ablation was about to start, immediately after ethanol injection, the RFA system did not work due to machine trouble. It took several minutes for the RFA system to be fixed and the ablation started approximately $5 \mathrm{~min}$ after the ethanol injection. This RFA system is equipped with an impedance monitoring system and the energy is continuously 
supplied until the overshoot of impedance, namely the rolloff phenomenon. In the above case, after the ablation had started, the roll-off phenomenon informing the termination of ablation occurred unexpectedly soon and the total ablation finished in a short time. Based on this observation, came the idea that the time-lag per formance of RFA after PEI may be more effective than PEI-RFA, especially in terms of energy requirement. Therefore, the volume of coagulated necrosis, total energy requirement and energy requirement per unit volume for whole and marginal coagulated necrosis were examined in time-lag and no time-lag PEI-RFA, using the Cool-tip RF system, which is preferentially used in our department.

\section{Patients and methods}

Patients and study design. Fifty-nine patients with HCC were allocated to receive time-lag or no time-lag PEI-RFA. Timelag PEI-RFA was performed on 33 nodules ranging between $1.0-4.0 \mathrm{~cm}$ in diameter in 24 cases (15 males and 9 females; mean age of 64 years). No time-lag PEI-RFA was performed on 44 nodules ranging between $1.2-5.5 \mathrm{~cm}$ in diameter in 35 patients (24 males and 11 females; mean age of 67 years). Informed consent was obtained from each patient (Table I).

Treatment. PEI-RFA was performed under the real-time ultrasonograpy (US) guidance with a $3.5-\mathrm{MHz}$ sector probe (Power Vision 5000 ; Toshiba Medical, Tokyo, Japan). To compare the effects of time-lag and no time-lag PEI-RFA, RFA was performed by using the Cool-tip RF System (Radionics, Burlington, VT, USA), as described in our previous reports (11-13). Briefly, a 17-gauge RFA needle with a 3-cm-long electrode was firstly inserted into the center of tumor, and then a 21-gauge PEI needle was inserted into the tumor through the same hole of attachment beside the echo probe. Pure ethanol (99.8\%) was slowly injected into the tumor. The volume of injected ethanol was always kept below the double volume of the estimated tumor volume. The ablation was performed under the impedance control. Ablation was started 5 min after the end of ethanol injection in time-lag PEI-RFA and immediately after in no time-lag PEI-RFA. Ablation was started from $30 \mathrm{~W}$ of power output followed by a stepwise increase of $20 \mathrm{~W}$ every 2-3 min. After ablation ended at $50 \mathrm{~W}$ of power output, the circulating cooling water was stopped and the temperature of the RFA electrode was checked. The ablation was terminated when the temperature of the RFA electrode reached $70^{\circ} \mathrm{C}$ (Fig. 1).

Evaluation of therapeutic efficacy. Five to seven days after treatment, helical dynamic computed tomography (CT) was performed to evaluate the therapeutic responses to time-lag and no time-lag PEI-RFA. Tumor necrosis was considered to be complete when no foci of early enhancement were seen around the tumor.

Calculation of energy requirement for ablation and the volume of marginal ablation area. Energy requirement for ablation was calculated as follows: energy $(\mathrm{J})=$ watt $(\mathrm{W}) \mathrm{x}$ duration of ablation (sec). The length of coagulated necrosis was measured from the late phase of helical dynamic CT. The approximation

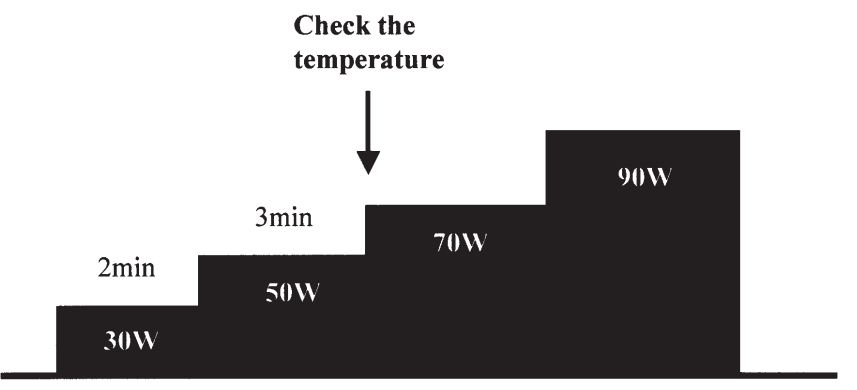

Figure 1 The procedure of ablation in time-lag and no time-lag PEI-RFA. Five min after (time-lag PEI-RFA) or immediately after (no time-lag PEIRFA) injection of ethanol into the tumor, the ablation was started from $30 \mathrm{~W}$ of power output followed by a stepwise increase of $20 \mathrm{~W}$ every 2-3 min. After the end of ablation at $50 \mathrm{~W}$ of power output, the circulating cooling water was stopped and the temperature of the RFA electrode was checked. When the temperature of the RFA electrode reached $70^{\circ} \mathrm{C}$, the ablation was terminated. The ablation was continued until the temperature reached over $65^{\circ} \mathrm{C}$.

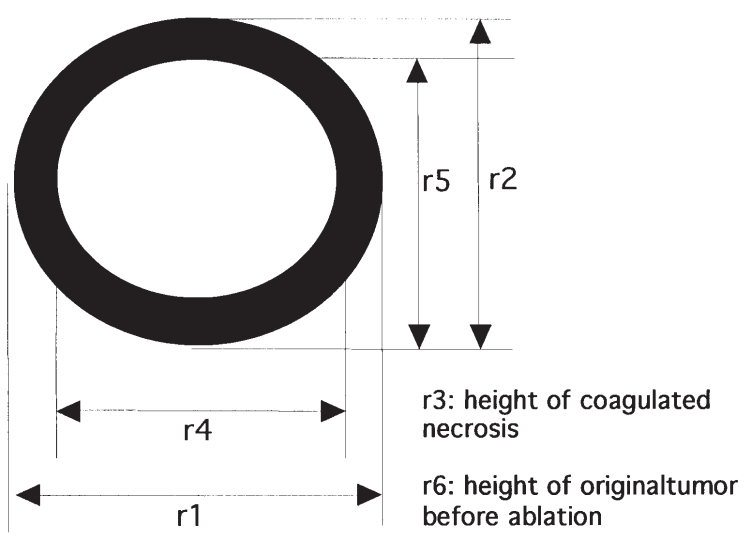

Figure 2. Schematic diagram for calculating the volume of the safety margin area. The white circle shows the HCC tumor before treatment and the black area shows the low density area around the tumor exhibited in the late phase of dynamic CT after treatment. The equation for caluculating the volume of the safety margin area is described in the patients and methods section.

volume of whole and marginal coagulated necrosis, and the energy requirement for ablation per unit volume were calculated as follows: whole coagulated necrosis $\left(\mathrm{V} 1 \mathrm{~cm}^{3}\right)=4 / 3 \pi$ x r1 $(\mathrm{cm})$ x r2 $(\mathrm{cm})$ x r3 $(\mathrm{cm}),(\mathrm{r} 1$, longest diameter/2; 2 , shortest diameter/2; $\mathrm{r}$, height/2); volume of original tumor before ablation $\left(\mathrm{V} 2 \mathrm{~cm}^{3}\right)=4 / 3 \pi$ x r4 $(\mathrm{cm})$ x r5 $(\mathrm{cm})$ x r6 $(\mathrm{cm}) /$ 2 , (r4, longest diameter/2; r5, shortest diameter/2; r6, height/2). The volume of marginal coagulated necrosis was calculated by subtracting V2 from V1. The scheme of each diameter of the whole coagulated necrosis and the original tumor before ablation is depicted in Fig. 2. Energy requirements for the whole coagulated necrosis per unit volume $\left(\mathrm{J} / \mathrm{cm}^{3}\right)$ and for the marginal coagulated necrosis per unit volume $\left(\mathrm{J} / \mathrm{cm}^{3}\right)=$ energy/ volume of whole coagulated necrosis, and energy requirements for the marginal coagulated necrosis per unit volume $\left(\mathrm{J} / \mathrm{cm}^{3}\right)=$ energy $/$ volume of marginal coagulated necrosis.

Statistical analysis. Statistical analysis was performed using Macintosh software StatView II (Version 5.0). Mann-Whitney's $\mathrm{U}$ test (non-parametric analysis) for calculating p-values 
Table I. Characteristics of patients enrolled in the present study.

\begin{tabular}{lcc}
\hline & $\begin{array}{c}\text { Time-lag } \\
\text { PEI-RFA }\end{array}$ & $\begin{array}{c}\text { No time-lag } \\
\text { PEI-RFA }\end{array}$ \\
\hline No. of patients & 24 & 35 \\
Male/Female & $15 / 9$ & $24 / 11$ \\
Age (years) & & \\
$\quad$ Mean & 64 & 67 \\
Range & $48-75$ & $45-80$ \\
Tumor size (cm) & & \\
Mean & 2.5 & 2.9 \\
Range & $1.0-4.0$ & $1.2-5.5$ \\
Injected ethanol (ml) & & 4.3 \\
Mean & 3.7 & $2.0-9.5$ \\
Range & $0.5-10$ & \\
Child-Pugh grade & & 23 \\
A & 16 & 11 \\
B & 7 & 1 \\
C & 1 & \\
\hline
\end{tabular}

expressing significant difference was used. Regression analysis was used to calculate correlation coefficients and p-values. Statistical significance was accepted when $\mathrm{p}<0.05$

\section{Results}

Comparative study of the volume of coagulated necrosis and the energy requirement in time-lag and no time-lag PEI-RFA. Fifty-nine patients with $\mathrm{HCC}$ were randomly divided into two groups. One group (24 patients) received time-lag PEI-RFA, while the other (35 patients) received no time-lag PEI-RFA. All patients underwent RFA therapy by means of the Cooltip RF system. No major adverse effects were observed in either group. Results of the comparison study of the volume of coagulated necrosis and the energy requirement per unit volume for inducing coagulation in both groups are summarized in Table II. The tumor size was approximately $2 \mathrm{~cm}$ in diameter in both groups and no significant difference was detected in either group. Although a small difference was detected in the height of coagulated necrosis, no significant difference was observed in the volume of coagulated necrosis and marginal coagulated necrosis between the groups. However, the total energy requirement and the energy requirement per unit volume for the whole and marginal coagulated necrosis were significantly lower in the time-lag PEI-RFA group than in the no time-lag group.

Relationship between the amount of injected ethanol and the volume of coagulated necrosis. We previously showed that the amount of injected ethanol was positively correlated with the volume of coagulated necrosis in no time-lag PEI-RFA. In the present study, the relationship between the amount of injected ethanol and the volume of coagulated necrosis was also confirmed in time-lag PEI-RFA. Significant positive correlation between the amount of injected ethanol and the volume of coagulated necrosis was observed in time-lag PEI-RFA (r=0.6, p=0.0025) (Fig. 3).

Representative case of HCC treated with time-lag PEI-RFA. By analyzing the effects of time-lag performance of RFA after PEI on energy requirement, one characteristic point became evident: time-lag PEI-RFA was shown to induce comparable coagulated necrosis with a lower energy requirement than no time-lag PEI-RFA.

One case with HCC successfully treated with time-lag PEI-RFA is shown in Fig. 4. An HCC tumor ( $2 \mathrm{~cm}$ in diameter) was located in the S3 region of the liver immediately under the diaphragm and the heart. The tumor was enhanced in the early vascular phase (Fig. 4A) and detected as a defect in the delay phase (Fig. 4B) of dynamic CT. HCC located immediately under the heart is difficult to treat with local treatment such as RFA or PEI because of the difficulty of puncturing the RFA electrode or PEI needle into the tumor. Moreover, RFA with a large amount of energy output should be avoided to prevent the adverse effects on the heart. Furthermore, the

Table II. Comparison of the volume of coagulated necrosis, total energy requirement and the energy requirement per unit volume for inducing coagulation in time-lag and no time-lag PEI-RFA.

\begin{tabular}{|c|c|c|c|c|c|c|c|c|c|c|c|c|}
\hline & $\begin{array}{l}\mathrm{T}-\mathrm{S} \\
(\mathrm{cm})\end{array}$ & $\begin{array}{l}\text { EtOH } \\
(\mathrm{ml})\end{array}$ & $\begin{array}{c}\mathrm{L} \\
(\mathrm{cm})\end{array}$ & $\begin{array}{c}\mathrm{S} \\
(\mathrm{cm})\end{array}$ & $\begin{array}{c}\mathrm{H} \\
(\mathrm{cm})\end{array}$ & $\begin{array}{c}\mathrm{V} \\
\left(\mathrm{cm}^{3}\right)\end{array}$ & $\begin{array}{c}\mathrm{M} \\
\left(\mathrm{cm}^{3}\right)\end{array}$ & $\begin{array}{c}\mathrm{P} \\
(\mathrm{W})\end{array}$ & $\begin{array}{c}\mathrm{T} \\
(\min )\end{array}$ & $\begin{array}{c}\text { T-ENE } \\
(\mathrm{J})\end{array}$ & $\begin{array}{c}\text { T-ENE/V } \\
\left(\mathrm{J} / \mathrm{cm}^{3}\right)\end{array}$ & $\begin{array}{c}\text { T-ENE/M } \\
\left(\mathrm{J} / \mathrm{cm}^{3}\right)\end{array}$ \\
\hline $\begin{array}{l}\text { Time-lag } \\
\text { PEI-RFA } \\
(\mathrm{n}=33)\end{array}$ & $1.9 \pm 0.2$ & $3.0 \pm 1.8$ & $3.5 \pm 0.6$ & $2.9 \pm 0.5$ & $3.1 \pm 0.6$ & $17.1 \pm 7.1$ & $15.3 \pm 7.2$ & $31.2 \pm 3.3$ & $2.7 \pm 0.8$ & $24144 \pm 9534$ & $1569 \pm 792$ & $1842 \pm 1048$ \\
\hline $\begin{array}{l}\text { No time-lag } \\
\text { PEI-RFA } \\
(n=44)\end{array}$ & $2.1 \pm 0.8$ & $3.6 \pm 2.0$ & $3.8 \pm 0.8$ & $3.0 \pm 0.6$ & $3.6 \pm 0.9$ & $21.8 \pm 13.4$ & $19.3 \pm 12.4$ & $62.1 \pm 32.1$ & $6.6 \pm 4.4$ & $47715 \pm 23547$ & $2781 \pm 1745$ & $7318 \pm 2733$ \\
\hline P-value & 0.18 & 0.24 & 0.27 & 0.61 & 0.012 & 0.37 & 0.31 & $<0.0001$ & 0.012 & $<0.0001$ & 0.0015 & 0.0034 \\
\hline
\end{tabular}

Thirty-three HCCs were treated with time-lag PEI-RFA by the Cool-tip RF System, while 44 HCCs were treated with no time-lag PEI-RFA using the same system. After treatment, the longest and shortest diameters, and the height of the coagulated necrosis were estimated by helical dynamic CT and the approximation volume of coagulated necrosis was calculated. T-S, tumor size; EtOH, amount of ethanol; L, longest diameter; S, shortest diameter; H, height; V, volume of coagulated necrosis; M, volume of margical coagulation; $\mathrm{P}$, power output; $\mathrm{T}$, time for ablation; T-ENE, total energy requirement; T-ENE/V, energy requirement per unit volume for whole coagulation; T-ENE/M, energy requirement per unit volume for inducing marginal coagulation. 


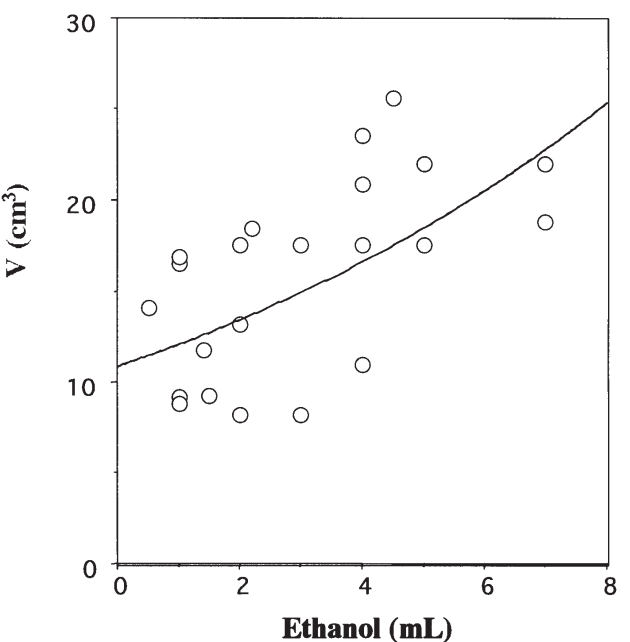

Figure 3. Relationship between the amount of ethanol injected and the volume of coagulated necrosis in time-lag PEI-RFA. Time-lag PEI-RFA was performed on $44 \mathrm{HCC}$ tumors. Ablation was performed using the Cool-tip RF system. The amount of ethanol injected into tumors positively correlated with the volume of coagulated necrosis $(r=0.6, p=0.0025)$.

patient was an old-aged female and her hepatic reserve capacity was low because of the progressed liver cirrhosis. Because RFA treatment with low output of energy was desirable, the patient underwent time-lag PEI-RFA. Five min after injecting $4 \mathrm{ml}$ of ethanol, the relatively short-time ablation compared with routine RFA was performed at $30 \mathrm{~W}$ for $3 \mathrm{~min}, 50 \mathrm{~W}$ for $3 \mathrm{~min}$ and $70 \mathrm{~W}$ for $2 \mathrm{~min}, 8 \mathrm{~min}$ in total. Dynamic CT taken after treatment showed the ablated region reaching $5 \mathrm{~cm}$ in the longest diameter and a sufficient safety margin around the tumor (Fig. 4C). This case also indicates that it is possible to obtain a sufficient ablated area with a low energy requirement by time-lag PEI-RFA.

\section{Discussion}

HCC is one of the most serious and common malignancies worldwide (14). As a treatment for HCC, surgical resection and liver transplantation are considered potentially curative. However, only a minority of patients with HCC are suitable for the surgical therapies because most patients have a very limited hepatic reserve due to underlying advanced liver cirrhosis. For the patients who are not candidates for surgical therapies, local treatments, including PEI, PAI, PMCT and RFA, are effective options. Among them, RFA is a new technology of local thermal ablation for $\operatorname{HCC}(5,15,16)$ and metastatic liver tumors $(1,7)$. This technique has become main-stream among non-surgical treatment modalities in clinical settings. However, the region of coagulated necrosis induced by RFA is limited and only considered applicable to tumors within a $3-\mathrm{cm}$ diameter. Furthermore, patients' liver function tests sometimes decline after RFA. RFA is sometimes terminated due to patients' complaints of pain. Therefore, the development of more effective and less invasive treatment modalities are desirable for local control of HCC.

A number of attempts have been applied to enhance the therapeutic effect of RFA by combining RFA with other treatment modalities, such as transcatheter arterial chemoembolization (17-21) and saline injection (22-26). We also developed novel combination therapies $(12,27-29)$. We reported that PEI-RFA could induce wider coagulated necrosis than routine RFA without adverse effects and could be applied to tumors that are difficult to treat with RFA alone (11). Furthermore, we recently obtained the result that PEI-RFA was able to induce comparable coagulated necrosis with a lower energy requirement than that of routine RFA (13). In PEI-RFA, RFA was started immediately after the injection of ethanol. However, as described in the introduction section, we accidentally experienced a case in which RFA was started several min after PEI, and recognized that time-lag PEI-RFA might be more effective than no time-lag PEI-RFA. In the present study, we demonstrated that the total energy requirement and the energy requirement per unit volume for whole and marginal coagulated necrosis were significantly lower under the same ablation condition in time-lag PEI-RFA than no time-lag PEI-RFA, although the total volume of coagulated necrosis and marginal coagulated necrosis was comparable between the groups. These results clearly indicate that time-lag performance of RFA after PEI is useful for decreasing the total energy requirement of ablation in PEI-RFA. Therefore, time-lag PEIRFA appears to be less invasive than no time-lag PEI-RFA.

We showed, in the present study, that an interval between PEI and RFA affected the energy requirement for inducing coagulated necrosis by PEI-RFA. It is known that ethanol causes the dehydration of tissue, including tumors. In the triggered case treated with the instrument with a LeVeen

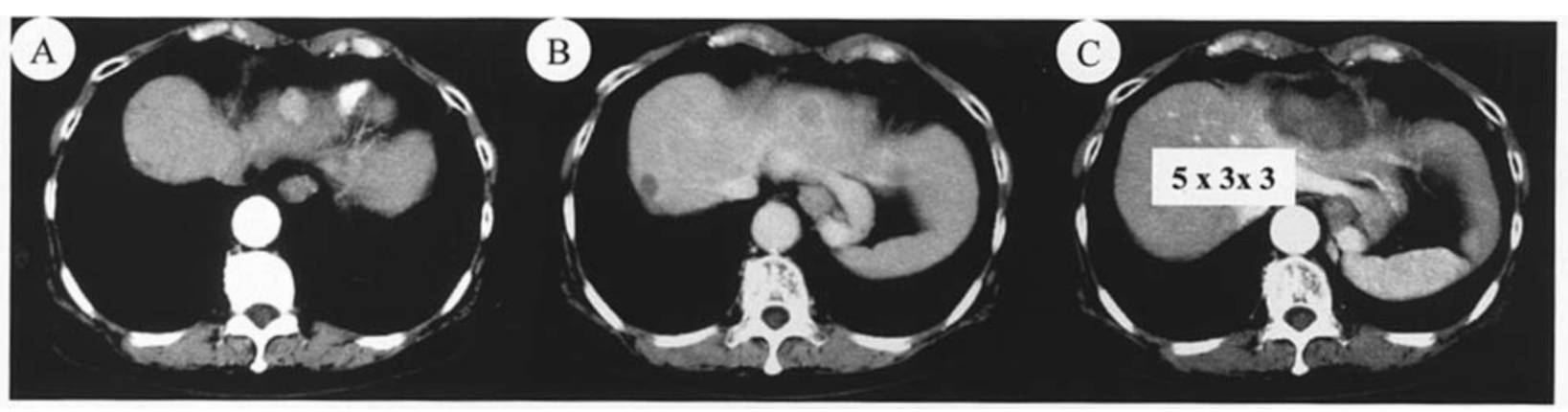

Figure 4. A case of HCC located immediately under the heart treated with time-lag PEI-RFA. Dynamic CT images before (A, early vascular phase; B, delay phase) and after (C, delay phase) time-lag PEI-RFA are shown. Five min after the injection of $4 \mathrm{ml}$ of ethanol into the tumor, RFA was performed at $30 \mathrm{~W}$ for $3 \mathrm{~min}, 50 \mathrm{~W}$ for $3 \mathrm{~min}$ and $70 \mathrm{~W}$ for $2 \mathrm{~min}$. Enough safety margin around the tumor was obtained after treatment. 
needle electrode, RFA was terminated by detecting the rolloff phenomenon. The roll-off phenomenon indicates that the ablated tumor tissue has been completely dehydrated. Therefore, by not treating the tumor for some time after ethanol injection, the tumor tissue may dehydrate to the same extent, and the dehydrated tumor may be more easily ablated by the following RFA. This may be a plausible explanation for the reduced total energy requirement of ablation in time-lag PEIRFA.

Since the detection system of hepatitis B and C viruses has progressed, the number of patients newly infected with hepatitis viruses is decreasing. On the contrary, the rate of oldaged patients with $\mathrm{HCC}$ is increasing year by year because HCC develops as a result of long-lasting viral infection. Oldaged patients are susceptible to serious side effects. It was recently reported that RFA had depressive effects on cellmediated immunity (30). Therefore, more effective but less invasive treatments are highly desirable in order to avoid the serious side effects, especially for old-aged patients. In this sense, time-lag PEI-RFA may be one of the most promising local treatments for HCC. A case with HCC located in S4 of the liver immediately under the diaphragm and the heart is shown in Fig. 4. For the treatment of HCC located immediately under the diaphragm or the heart, use of artificial pleural effusion followed by RFA is another treatment option because it can make the tumor more visible by US. However, in this patient, although the puncture of needles was actually difficult due to the heart being located immediately over the tumor, the HCC was successfully treated with time-lag PEI-RFA without artificial pleural effusion. Moreover, although the ablation was performed with a very low output and in a short duration, the ablated area sufficiently covered the tumor. Thus, time-lag PEI-RFA is very convenient for the treatment of tumors that are difficult to treat with routine RFA alone.

In conclusion, the total energy requirement and the energy requirement per unit volume for inducing coagulated necrosis were significantly lower in time-lag PEI-RFA than in no timelag PEI-RFA, suggesting that time-lag PEI-RFA is less invasive than routine RFA alone. This local treatment may be important for the present situation in which the majority of patients with HCC are of an older age.

\section{References}

1. Curley SA, Izzo F, Delrio P, Ellis LM, Granchi J, Vallone P, Fiore F, Pignata S, Daniele B and Cremona F: Radiofrequency ablation of unresectable primary and metastatic hepatic malignancies: Results in 123 patients. Ann Surg 230: 1-8, 1999.

2. Livraghi T, Goldberg SN, Lazzaroni S, Meloni F, Ierace T, Solbiati L and Gazelle GS: Hepatocellular carcinoma: radiofrequency ablation of medium and large lesions. Radiology 214 : 761-768, 2000.

3. Allgaier HP, Deibert P, Zuber I, Olschewski M and Blum HE: Percutaneous radiofrequency interstitial thermal ablation of small hepatocellular carcinoma. Lancet 353: 1676-1677, 1999.

4. Goldberg SN, Gazelle GS, Solbiati L, Livraghi T, Tanabe KK, Hahn PF and Mueller PR: Ablation of liver tumors using percutaneous RF therapy. Am J Roentgenol 170: 1023-1028, 1998.

5. Curley SA, Izzo F, Ellis LM and Vauthey JN: Radiofrequency ablation of hepatocellular cancer in 110 patients with cirrhosis. Ann Surg 232: 381-391, 2000.

6. Solbiati L, Goldberg SN, Ierace T, Livraghi T, Meloni F, Dellanoce M, Sironi S and Gazelle GS: Hepatic metastases: percutaneous radio-frequency ablation with cooled-tip electrodes. Radiology 205: 367-372, 1997.
7. Solbiati L, Lerace T, Goldberg SN, Sironi S, Livraghi T, Fiocca R, Servadio G, Rizzatto G, Mueller PR, Del Maschio A and Gazelle GS: Percutaneous US-guided radio-frequency tissue ablation of liver metastases: treatment and follow-up in 16 patients. Radiology 202: 195-203, 1997.

8. Lencioni RA, Allgaier H-P, Cloni D, Olschewski M, Deibert P, Crocetti L, Frings H, Laubenberger J, Zuber I, Blum HE and Bartolozzi C: Small hepatocellular carcinoma in cirrhosis: randomized comparison of radio-frequency thermal ablation versus percutaneous ethanol injection. Radiology 228: 235-240, 2003.

9. Livraghi T, Goldberg SN, Lazzaroni S, Meloni F, Solbiati L and Gazelle GS: Small hepatocellular carcinoma: treatment with radio-frequency ablation versus ethanol injection. Radiology 210: 655-661, 1999

10. Abdalla EK, Vauthey JN, Ellis LM, Ellis V, Pollock R, Broglio KR, Hess K and Curley SA: Recurrence and outcomes following hepatic resection, radiofrequency ablation and combined resection/ablation for colorectal liver metastases. Ann Surg 239: 818-825, 2004.

11. Kurokohchi K, Watanabe S, Masaki T, Hosomi N, Funaki T, Arima K, Yoshida S, Nakai S, Murota M, Miyauchi Y and Kuriyama S: Combination therapy of percutaneous ethanol injection and radiofrequency ablation against hepatocellular carcinomas difficult to treat. Int J Oncol 21: 611-615, 2002.

12. Kurokohchi K, Watanabe S, Masaki T, Hosomi N, Funaki T, Arima K, Yoshida S, Miyauchi Y and Kuriyama S: Combined use of percutaneous ethanol injection and radiofrequency ablation for the effective treatment of hepatocellular carcinoma. Int $\mathbf{J}$ Oncol 21: 841-846, 2002.

13. Kurokohchi K, Watanabe S, Masaki T, Hosomi N, Miyauchi Y, Himoto T, Kimura Y, Nakai S, Deguchi A, Yoneyama H, Yoshida $\mathrm{S}$ and Kuriyama S: Comparison between combination therapy of percutaneous ethanol injection and radiofrequency ablation and radiofrequency ablation alone for patients with hepatocellular carcinoma. World J Gastroenterol 11: 1426-1432, 2005.

14. Okuda K: Hepatocellular carcinoma. J Hepatol 32: 225-237, 2000.

15. Goldberg SN, Gazelle GS, Compton CC, Mueller PR and Tanabe KK: Treatment of intrahepatic malignancy with radiofrequency ablation: radiologic-pathologic correlation. Cancer 88: 2452-2463, 2000.

16. Jiang H, Liu L, Piao D, Xu J, Zheng M, Zhu A, Qi S, Zhang W and Wu L: Clinical short-term results of radiofrequency ablation in liver cancers. World J Gastroenterol 8: 624-630, 2002.

17. Rossi S, Garbagnati F, Lencioni R, Allgaier H-P, Marchiano A, Fornari F, Quaretti P, Di Tolla G, Ambrosi C, Mazzaferro V, Blum HE and Bartolozzi C: Percutaneous radio-frequency thermal ablation of non-resectable hepatocellular carcinoma after occlusion of tumor blood supply. Radiology 217: 119-126, 2000.

18. Buscarini L, Buscarini E, Di Stasi M, Quaretti P and Zangrandl A: Percutaneous radiofrequency thermal ablation combined with transcatherter arterial embolization in the treatment of large hepatocellular carcinoma. Ultraschall Med 20: 47-53, 1999.

19. Yamasaki T, Kurokawa F, Shirahashi H, Kusano N, Hironaka K and Okita K: Percutaneous radiofrequency ablation therapy with combined angiography and computed tomography assistance for patients with hepatocellular carcinoma. Cancer 91: 1342-1348, 2001.

20. Koda M, Murawaki Y, Mitsuda A, Oyama K, Okamoto K, Idobe Y, Suou T and Kawasaki H: Combination therapy with transcatheter arterial chemoembolization and percutaneous ethanol injection compared with percutaneous ethanol injection alone for patients with small hepatocellular carcinoma. Cancer 92: 1516-1524, 2001.

21. Kitamoto M, Imagawa M, Yamada H, Watanabe C, Sumioka M, Satoh O, Shimamoto M, Kodama M, Kimura S, Kishimoto K, Okamoto Y, Fukuda Y and Dohi K: Radiofrequency ablation in the treatment of small hepatocellular carcinomas: comparison of the radiofrequency effect with and without chemoembolization. Am J Roentgenol 181: 997-1003, 2003.

22. Livraghi T, Goldberg SN, Monti F, Bizzini A, Lazzaroni S, Meloni F, Pellicano S, Solbiati L and Gazelle GS: Salineenhanced radio-frequency tissue ablation in the treatment of liver metastases. Radiology 202: 205-210, 1997.

23. Honda N, Guo Q, Uchida H, Ohishi H and Hiasa Y: Percutaneous hot saline injection therapy for hepatic tumors: an alternative to percutaneous ethanol injection therapy. Radiology 190: 53-57, 1994. 
24. Burdio F, Guemes A, Burdio JM, Navarro A, Sousa R, Castiella T, Cruz I, Burzaco O, Guirao X and Lozano R: Large hepatic ablation with bipolar saline-enhanced radiofrequency: an experimental study in in vivo porcine liver with a novel approach. J Surg Res 110: 193-201, 2003.

25. Hansler J, Frieser M, Schaber S, Kutschall C, Bernatik T, Muller W, Becker D, Hahn EG and Strobel D: Radiofrequency ablation of hepatocellualar carcinoma with a saline solution perfusion device: a pilot study. J Vasc Interv Radiol 14: 575-580, 2003.

26. Lee JM, Han JK, Kim SH, Lee JY, Kim DJ, Lee MW, Cho GG, Han CJ and Choi BI: Saline-enhanced hepatic radiofrequency ablation using a perfused-cooled electrode: comparison of dual probe bipolar mode with monopolar and single probe bipolar modes. Korean J Radiol 5: 121-127, 2004.

27. Kurokohchi K, Masaki T, Miyauchi Y, Funaki T, Yoneyama H, Miyoshi H, Yoshida S, Himoto T, Morishita A, Uchida N, Watanabe $S$ and Kuriyama S: Percutaneous ethanol and lipiodol injection therapy (PELIT) for hepatocellular carcinoma. Int J Oncol 24: 381-387, 2004.
28. Kurokohchi K, Masaki T, Himoto T, Deguchi A, Nakai S, Yoneyama H, Yoshida S, Kimura Y, Inoue H, Kinekawa F, Kimura Y, Yoshitake A, Izuishi K, Watanabe S and Kuriyama S: Successful laparoscopic radiofrequency ablation of hepatocellular carcinoma adhered to the mesentery after transcatheter arterial embolization. Oncol Rep 13: 65-68, 2005.

29. Kurokohchi K, Masaki T, Miyauchi Y, Hosomi N, Yoneyama $\mathrm{H}$, Yoshida S, Himoto T, Deguchi A, Nakai S, Inoue H, Watanabe S and Kuriyama S: Efficacy of combination therapies of percutaneous or laparoscopic ethanol-lipiodol injection and radiofrequency ablation. Int J Oncol 25: 1737-1743, 2004.

30. Yu HC, Moon JI, Jin ZW, Lee DY, Kim CY, Song CH and Cho BH: Effect of radiofrequency ablation of the liver on cellmediated immunity in rats. World J Gastroenterol 29: 739-743, 2005 